\title{
PEMETAAN JALUR WISATA SPIRITUAL DI KECAMATAN NUSA PENIDA
}

\section{Ni Komang Artini ${ }^{1}$, I Gede Budiarta ${ }^{2 *}$}

Prodi Pendidikan Geografi, Universitas Pendidikan Ganesha, Singaraja, Indonesia

\section{A R T I C L E I N F O}

Article history:

Received 19 Desember 2018

Received in revised form 6 Maret 2018

Accepted 12 MAret 2018 Available online 31 Maret 2018

\section{Kata Kunci:}

Pemetaan

Jalur

Wisata

Spiritual

Keywords

Mapping

Spiritual

\begin{abstract}
A B S T R A K
Penelitian ini bertujuan untuk (1) Mengidentifikasi karakteristik wisata spiritual di Nusa Penida dan (2)memetakan jalur wisata spiritual di Kecamatan Nusa Penida. Objek penelitiannya adalah tentang karakteristik wisata spiritual dan memetakan jalur wisata spiritual. Subjek penelitiannya adalah pemangku pada setiap pura, sopir dan kepala desa di Nusa Penida. Metode yang digunakan pada penelitian ini adalah metode observasi lapangan dan wawancara. Analisis data yang digunakan adalahdeskriptif kualitatif,dengan mempertimbangkan hasil observasi lapangan dan wawancara mengenaiwisata spiritualyang dikaji dalam penelitian ini.Hasil penelitian ini menunjukan bahwa :(1)Karakteristik wisata spiritual di Nusa Penida memiliki yaitu tipologi bangunan, susunan pura, orientasi pura, sasaran yang dipuja, penyungsung pura, dan fungsi pura. (2) urutan jalur wisata spiritual dari keempat pura dimulai dari yang pertama sampai terakhir yaitu Pura Goa Giri Putri, Pura Batu Medau, , Pura Puncak Mundi, dan Pura Goa Giri Putri.
\end{abstract}

A B S T R A C T

This research was conducted which aimed to (1) Identify the characteristics of spiritual tourism in Nusa Penida and (2) Map the spiritual tourism route in Nusa Penida Sub-district. The object of this research was the characteristics of spiritual tourism and mapping the spiritual tourist route. The research subjects are the stakeholders of each temple in Nusa Penida, all spiritual travel drivers and the village chief in Nusa Penida. The method used in collecting data in this research was field observation and interview. The data analysis used was descriptive qualitative, by considering the result of the field observation and the interview about spiritual tourism which studied in this research. The results of this study showed that: (1) Thespiritual tourism in Nusa Penida has some characteristicsnamely building typology, temple arrangement, temple orientation, revered target, templestakeholders, and temple function. (2) The sequence of the spiritual tour of the four temples in Nusa Penida started from the first to the last temple namely Goa GiriPutri Temple, BatuMedau Temple, PuncakMundi Temple, and Penataran Ped Temple.

\footnotetext{
* Corresponding author.

E-mail addresses:artinikomang96@gmail.com(Penulis Pertama), budiartagd geo@yahoo.co.id(Penulis Kedua)
} 


\section{Pendahuluan}

Perkembangan dunia pariwisata yang secara signifikan beberapa tahun terakhir mempunyai dampak pada perkembangan perekonomian suatu negara. Selain peningkatan devisa negara, pariwisata juga berperan dalam bentuk perluasan lapangan kerja, peningkatan pertumbuhan ekonomi, peningkatan kesejahteraan masyarakat, kemiskinan, dan pemerataan pembangunan spasial. Perkembangan kepariwisataan bertujuan memberikan keuntungan baik bagi wisatawan maupun warga setempat. pariwisata dapat memberikan kehidupan yang standar kepada warga setempat melalui keuntungan ekonomi yang didapat dari tempat tujuan wisata (Marpaung, 2002). Tambahan perkembangan infrastruktur dan fasilitas rekreasi, keduanya menguntungkan wisatawan dan warga setempat, sebaliknya kepariwisataan dikembangkan melalui penyediaan tempat tujuan wisata. Pertumbuhan pada sektor pariwisata yang pesat maka usaha ekonomi juga mengalami pertumbuhan yang sama sesuai dengan peningkatan pendapatan daerah seperti pendapatan PDRB (Product Domestic Regional Bruto) (Herman \& Supriadi, 2017).

Berbagai daerah memiliki rencana induk pengembangan pariwisata dalam skala mikro untuk pengembangan objek atau atraksi wisata maupun rencana pengembangan secara regional atau nasional (Arjana, 2016). Objek daya tarik wisata sangat hubungnnya dengan travel motivation dan travel fashion. Di dalam suatu perjalanan wisata, tentu dilihat dari suatu jalan/paket wisata agar suatu perjalanan wisata jelas lebih dikenal merata dan menarik. Paket wisata merupakan terjemahan yang cepat untuk istilah tour package yang merupakan sebagai sesuatu rencana atau acara perjalanan wisata yang telah tersusun secara tetap, dengan harga tertentu yang telah termasuk pula biaya-biaya untuk transfer/pengangkutan, fasilitas akomodasai/hotel, serta darma wisata di kota/kota-kota, objek-objek wisata dan atraksi-atraksi yang telah tercantum dalam acara itu (Suyitno,2001).

Terdapat dua paham, yaitu pertama religi sebagai bagian hidup kesusilaan manusia dan memiliki nilai susila yang tinggi. Gagasan tersebut telah diuraikan secara filosofi oleh Kant. Kedua, religi tergolong dalam alam hidup manusia. Religi kedua ini menghendaki tiga kebenaran utama, yaitu percaya bahwa Tuhan ada, percaya kepada hukum kesusilaan alamiah, dan pada roh yang abadi. Dari dua konsep religi semacam ini, pada kenyataannya pengertian kedua yang menarik perhatian peneliti budaya. Munculnya istilah pariwisata spiritual atau wisata spiritual tidak bisa terlepas dengan adanya gerakan sumber terjadinya segala sesuatu dan manusia adalah bagian dari kekuatan semesta itu. Dengan kata lain, orang menyebut kekuatan semesta itu sebagai kekuatan besar (makro kosmos), dan manusia adalah kekuatan kecil (mikro kosmos). Kalau dalam matematika dikenal himpunan bagian, maka dalam kaitan ini manusia merupakan himpunan bagian dari makro kosmos. Menurut Damasdino (2015) untuk tujuan perencanaan kepariwisataan di suatu objek harus diperlukan data karakteristik wisatawan berdasarkan kebutuhan atas riil kelompok/segmentasi wisatawan bukan berdasarkan atas variabel tunggal yang bersifat linier.

Wisata Religi merupakan jenis wisata keagamaan (pileimge tour) atau wisata yang bermotif spiritual. Wisata Religi dalam pengertian yaitu telah menarik perhatian 
peneliti budaya, karena di dalamnya sering terdapat muatan budaya yang unik. Terdapat dua paham, yaitu pertama religi sebagai bagian hidup kesusilaan manusia dan memiliki nilai susila yang tinggi. Bali dan pariwisata tidak dapat dipisahkan, sebagai daerah tujuan wisata utama, kekayaan dan keindahan alam, serta keunikan seni dan budayanya menjadi daya tarik utama. Bali dikenal sebagai Pulau Dewata karena memiliki kekhasan yang dipengaruhi oleh agama Hindu (Dwiyasa \& Citra, 2014). Selain di Bali ada juga di Pulau Nusa Penida, yang penduduknya menganut Agama Hindu dan juga banyak penduduk yang religius (Sukadi, 2001).

Saat ini pariwisata yang ada di Bali telah tumbuh dan berkembang sangat pesat seiring dengan waktu yang berjalan (Suwirmayanti, 2016). Perkembangan tidak hanya di Pulau Bali melainkan juga di pulau sekitarannya seperti Pulau Nusa Penida. Pulau Nusa Penida terletak di sebelah barat daya Pulau Bali yang merupakan bagian dari wilayah Kecamatan di Kabupaten Klungkung. Nusa Penida terkenal dengan banyak wisata yaitu wisata bahari, wisata alam, dan wisata spiritual. Pariwisata spiritual merupakan salah satu bentuk dari kegiatan pariwisata tertua, dan terlibat dalam sektor yang signifikan berkembang dari pasar pariwisata global (Aditya, Suwena, \& Sudana, 2016). Semakin banyaknya pemedek atau masyarakat lokal yang melakukan persembahyangan di Nusa penida sehingga masyarakat Nusa Penida menekankan tentang wisata spiritual dan masyarakat Nusa Penida sebagian besar bersifat religius yang dapat dilihat dari keberadaan pura yang ada di Nusa Penida diantaranya yaitu, Pura Goa GiriPutri, Pura Batu Medau, Pura Puncak Mundi, dan Pura Dalem Penataran Ped.

Pemetaan jalur wisata religi ini perlu diterapkan untuk mempermudah wisatawan atau pelancong atau pemedek untuk melakukan yang namanya Tirta Yatra yang mana pemedek memulai perjalanan dari pura pertama hingga pura terakhir. Pemetaan jalur wisata spiritual ini dibuat untuk memperbaiki intensitas wisatawan agar semakin meningkat selain itu untuk memperbaiki perekonomian masyarakat setempat. Pada saat ini belum adanya pemetaan jalur tersebut, maka penelitian ini dibuat untuk memberikan manfaat bagi pemerintah dan masyarakat. Belum diketahuinya urutan jalur wisata yang ditempuh atau belum dikenalnya jalur perjalanannya, sehingga menarik untuk mengadakan penelitian tentang " Pemetaan Jalur Wisata Spiritual Di Kecamatan Nusa Penida”. Permasalahan pada penelitian ini (1) bagaimana karakteristik wisata spiritual di Kecamatan Nusa Penida, (2) bagaimana jalur wisata spiritual di Kecamatan Nusa Penida. Tujuan dari penelitian ini (1) mengidentifikasi karakteristik wisata spiritual di Kecamatan Nusa Penida, (2) memetakan jalur wisata spiritual di Kecamatan Nusa Penida.

\section{Metode}

Penelitian ini dilakukan di Kecamatan Nusa Penida. Objek dalam penelitian wisata spiritual yaitu Pura yang terletak di Kecamatan Nusa Penida. Memperhatikan Objek Penelitian tersebut, yang menjadi subjek dalam penelitian ini adalah pemangku pada setiap pura, kepala desa dan sopir angkutan darat. 
Penelitian ini menggunakan racangan penelitian deskriptif. Data yang digunakan adalah data primer dan sekunder. Data sekunder bersumber dari Badan Pusat statistik Kabupaten Klungkung. Data primer yang telah dikumpulkan selanjutnya akan dianalisis menggunakan analisis deskriptif kualitatif dengan menggunakan pendekatan keruangan. karakteristik wisata spiritual di Kecamatan Nusa Penida dan menentukan jalur wisata spiritual di Kecamatan Nusa Penida.Selanjutnyadata mengenai jalur wisata dipetakan menggunakan projek SIG

\section{Hasil dan pembahasan}

\subsection{Karakteristik Wisata Spiritual}

\section{a. Pura Goa Giri Putri}

Pura Goa Giri Putri terletak di Karangsari, Desa Suana, Kecamatan Nusa Penida, Kabupaten Klungkung Bali. Pura Goa Giri Putri ini berfungsi sebagai tempat pemujaan bagi umat Hindu. Dalam perkembangannya, manusia memikirkan pola kehidupan baru dengan pola permukiman tetap serta dukungan teknologi yang kian canggih agar mampu mewujudkan kehidupan yang lebih baik. Meski kehidupan kian modern, namun kenyataan menunjukkan bahwa tradisi prasejarah atau kebudayaan di dalam goa tetap eksis dengan fungsi yang terus berkembang atau berubah.

Terdapat 5 tempat bersembahyang / pelinggih. Pada saat berkunjung (tangkil) ke Pura Goa Giri Putri. Sampai di atas, bertemu pelinggih pertama (Pelinggih Hyang Tri Purusa) berupa sebuah Padmasana yang berada persis di depan mulut goa. Tipologi bangunan pelinggih pada pura ini yaitu arah barat ke timur (dauh-dangin) yang malinggih di pelinggih itu adalah kekuatan Ida Sang Hyang Widhi dalam perwujudannya sebagai Hyang Tri Purusa (ajaran Siwa Sidantha) yang terdiri atas Paramasiwa, Sadasiwa dan Siwatma.Persembahyang di Pelinggih Tri Purusa, pemedek lanjut memasuki areal Goa Giri Putri. Begitu melewati terowongan, pemedek kembali menemukan pelinggih kedua, yakni Pelinggih Hyang Wasuki yang berupa Sapta Petala. Tipologi bangunan pelinggih pada pura ini yaitu arah utara ke selatan (kaja-kelod) dengan orientasi pura menghadap ke gunung.Usai melakukan persembahyangan di Pelinggih Hyang Wasuki, pemedek melanjutkan persembahyangan di pelinggih ketiga berupa Padmasana. Pelinggih ini merupakan tempat berstananya Hyang Giripati/Siwa, Penyineban Ida Batara dan tempat pelukatan. Tipologi bangunan pelinggih pada pura ini yaitu arah barat ke timur (dauh-dangin).

Persembahyangan berikutnya adalah pelinggih keempat yakni tempat berstananya Hyang Giri Putri. Tipologi bangunan pelinggih pada pura ini yaitu arah utara ke selatan (kaja-kelod) dengan orientasi pura menghadap ke gunung.Terakhir, Pelinggih Hyang Siwa Amerta, Sri Sedana/Ratu Syahbandar dan Dewi Kwam im. Tipologi bangunan pelinggih pada pura Kwam Im yaitu barat ke timur (dauh-dangin). Pemedek atau pengunjung yang datang ke Pura ini tidak hanya dari Nusa Penida melainkan dari seluruh Bali yang melakukan persembahyangan atau Tirta Yatra ke Pura ini, tidak hanya masyarakat Hindu yang berkunjung melainkan ada masyarakat luar atau Tourist yang berkunjung ke Pura ini, ada yang melakukan persembahyangan dan ada juga yang hanya mengambil dokumentasi. 


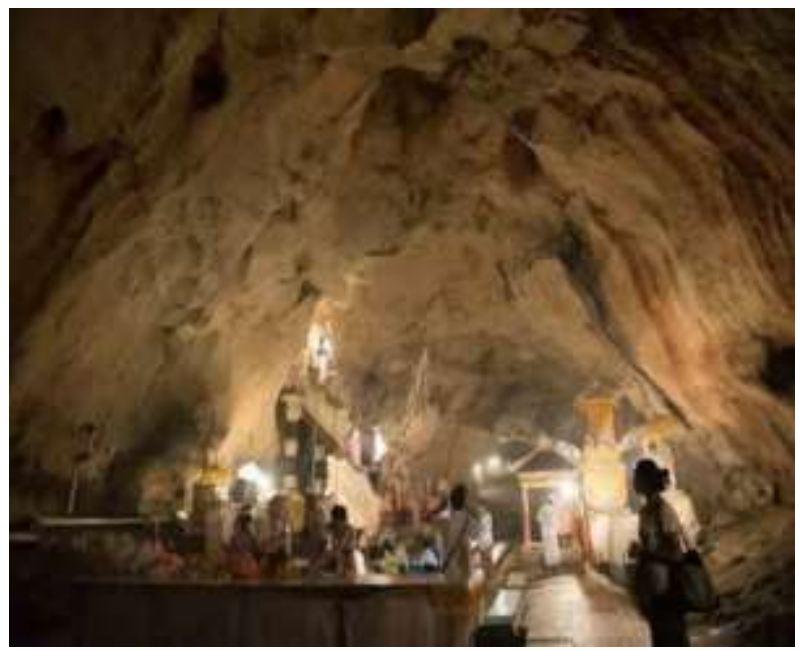

Gambar 1. Pura Goa Giri Putri

\section{b. Pura Batu Medau}

Pura Batu Medau terletak di desa Suana, Kecamatan Nusa Penida, Kabupaten Klungkung, Bali di sebelah barat Desa Semaya. Pura Batu Medau merupakan pura Sad Kahyangan. Nama Batu Medau berasal dari perahu medah batu atau perahu yang membelah batu. Terbentuknya Pura batu Medau dapat dilihat sejarah yaitu cerita yang mengisahkan tentang I Renggan salah satu cucu Dukuh Jumpungan yang mau menaklukkan Bali dengan perahu saktinya. Ia diyakini mampu membuat setiap daratan yang dilewati perahu tersebut menjadi lautan. Kemudian Bhatara Toh Langkir yang menegetahui keinginan tersebut maka dibuatlah I Renggan tidak bisa mengendalikan perahu tersebut dan tertidur pulas.

Perahu tersebut terdampar di Manggis Karangasem dan menabrak pulau yang ada di sana sehingga pulau tersebut terbelah dan menyisakan pulau kecil-kecil seperti disekitaran Padang Bai, kemudian dari kegagalannya tersebut I Renggan kembali ke Nusa Penida tepatnya di timur pulau bermaksud menambatkan perahunya di sana, ternyata perahu yang tidak terkendali sempurna malah lewat ke pantai dan membelah gundukan batu yang ada di sana. Bekas perahu I Renggan tersebut dibuat suatu tempat pemujaan yang kini di sebut dengan Pura Batu Medau.

Pura Batu Medau memiliki 3 lokasi pura yaitu Pura pertama atau Pura Segara menghadap ke selatan (kelod) dengan memiliki 2 susunan pura yaitu halaman luar dan halaman dalam yang berstana di pura ini yaitu dewa Baruna, Pura kedua atau Pura Taman menghadap ke selatan (kelod) dengan memiliki 2 susunan pura yaitu halaman luar dan halaman dalam, yang berstanan di pura ini yaitu Dewi Gangga, Pura ke tiga atau Pura Penataran Agung menghadap ke selatan (kelod) dengan memiliki 3 susunan pura yaitu halaman luar, halaman tengah, dan halaman dalam, yang berstana di pura ini yaitu Ida Ratu Mas Landung. Orientasi ketiga pura ini menghadap ke gunung.

Pemedek atau pengunjung yang datang ke Pura ini tidak hanya dari Nusa Penida melainkan dari seluruh Bali yang melakukan persembahyangan atau Tirta Yatra ke Pura ini, tidak hanya masyarakat Hindu yang berkunjung melainkan ada masyarakat luar atau 
Tourist yang berkunjung ke Pura ini, ada yang melakukan persembahyangan dan ada juga yang hanya mengambil dokumentasi.

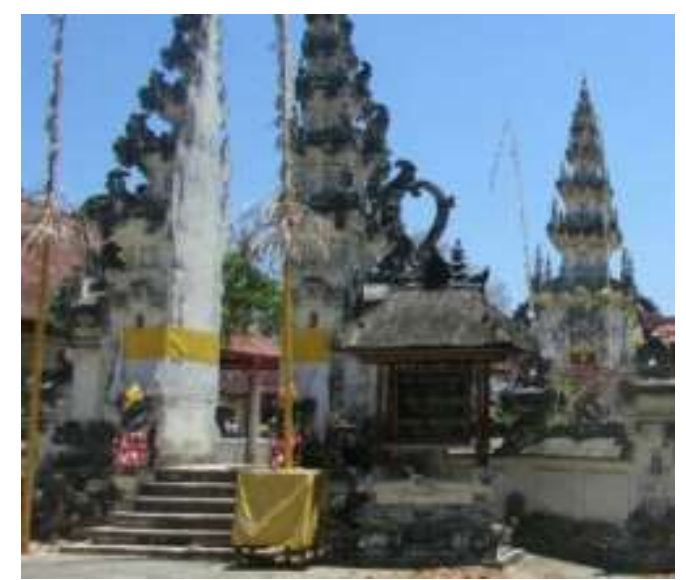

Gambar 2. Pura Batu Medau

c. Pura Puncak Mundi

Pura Puncak Mundi terletak di Dusun Rata, Desa Klumpu, Kecamatan Nusa Penida Bali. Pura initerdiri dari tiga paleban pura yaitu persembahyangan pertama Pura Taman (Beji) yang merupakan tempat berstananya Ida Bhatara Dewi Gangga. Tipologi bangunan pelinggih pada persembahyangan pertama yaitu dari barat ke timur (dauhdangin) dengn orientasi Pura menghadap ke gunung. Pura Taman memiliki dua susunan Pura yaitu jeroan dan jaba sisi atau dalam dan halaman luar.Persembahyangan kedua adalah Pura Dalem Kerangkeng yaitu tempat berstananya Ida Bhatara Durga. Tipologi bangunan pelinggih pada Pura kedua yaitu arah utara ke selatan (kaja-kelod) dengan orientasi Pura menghadap ke Gunung. Pura Dalem Kerangkeng juga memiliki dua susunan Pura yaitu jeroan dan jaba sisi atau dalam dan halaman luar.Persembahyangan ketiga merupakan yang terakhir yang Pura Puncak Mundi yang merupakan tempat berstananya Ida bhatara siwa yang menjelma sebagai Dukuh Cemeng. Tipologi bangunan pelinggih pada Pura ketiga menghadap timur (Dangin) yaitu ke arah terbitnya matahari. Pura Puncak Mundi memiliki Tri Mandala atau tiga susunan Pura yaitu jaba sisi, jaba tengah, dan jeroan atau halaman luar, halaman tengah dan halaman dalam.

Pemedek atau pengunjung yang datang ke Pura ini tidak hanya dari Nusa Penida melainkan dari seluruh Bali yang melakukan persembahyangan atau Tirta Yatra ke Pura ini, tidak hanya masyarakat Hindu yang berkunjung melainkan ada masyarakat luar atau Tourist yang berkunjung ke Pura ini, ada yang melakukan persembahyangan dan ada juga yang hanya mengambil dokumentasi. 


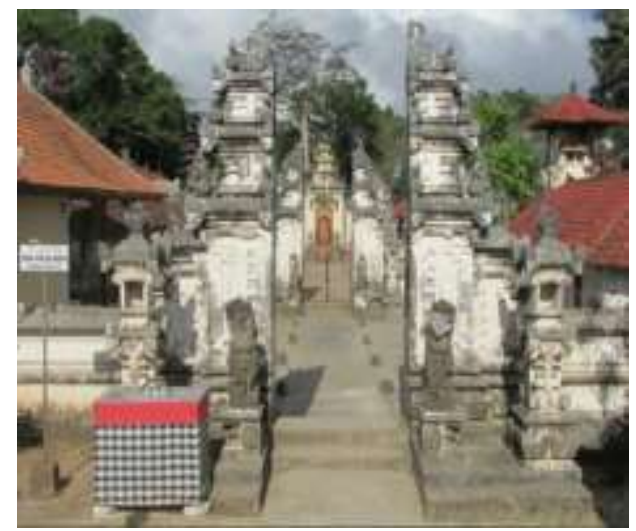

Gambar 3. Pura Puncak Mundi

\section{d. Pura Penataran Ped}

Pura Penataran Agung Ped terletak di Desa Ped, Kecamatan Nusa Penida, Kabupaten Klungkung, Bali. Ada empat lokasi pura yang bersatu pada areal Pura Penataran Agung Ped. Pura Segara, sebagai tempat berstananya Batara Baruna. Tipologi bangunan Pelinggih pada Pura Segara menghadap utara ke selatan (kaja-kelod) dengan orientasi pura menghadap ke Gunung. Pura Segara memiliki 2 susunan pura yaitu jaba sisi dan jeroan (bagian lur dan bagian dalam). Beberapa meter mengarah ke selatan ada Pura Taman yaitu tempat berstananya Dewa Wisnu. Tipologi pelinggih pada pura Taman menghadap utara ke selatan (kaja-kelod) dengan orientasi pura menghadap ke gunung. Pura Taman memiliki 3 susunan pura yaitu jaba sisi, jaba tengah dan jeroan (halaman luar, halaman tengah dan halaman dalam).

Mengarah ke baratnya lagi, ada Pura Dalem Ida Ratu Gede Mecaling tempat berstananya Ratu Gede. Tipologi bangunan pelinggih pada pura Penataran Ratu Gede Mecaling yaitu arah utara ke selatan (kaja-kelod) dengan orientasi pura menghadap ke gunung. Pura Ratu Gede Mecaling memiliki 2 susunan pura yaitu jaba sisi dan jeroan (halaman luar dan dalam). Di sebelah timurnya ada Pura Penataran agung Dalem Peed yaitu tempat berstananya Ratu Mas. Tipologi bangunan pelinggih pada pura Ratu Mas yaitu utara ke selatan (kaja-kelod) dengan orientasi pura menghadap ke gunung. Pura Ratu Mas memiliki 3 susunan pura yaitu jaba sisi, jaba tengan dan jeroan (halaman luar, halaman tengan dan halaman dalam).Pemedek atau pengunjung yang datang ke Pura ini tidak hanya dari Nusa Penida melainkan dari seluruh Bali yang melakukan persembahyangan atau Tirta Yatra ke Pura ini, tidak hanya masyarakat Hindu yang berkunjung melainkan ada masyarakat luar atau Tourist yang berkunjung ke Pura ini, ada yang melakukan persembahyangan dan ada juga yang hanya mengambil dokumentasi.

Tipologi bangunan pelinggih pada pura yang dimaksud adalah arah pura, dalam wisata spiritual di Kecamatan Nusa Penida arah pura ini berbeda-beda dan dalam Agama Hindu pembangunan pura sesuai dengan dewata nawa sanga yang artinya sembilan penjuru arah mata angin menurut Hindu. Adapun yang dimaksud yaitu

1) Arah timur sebagai Dewa Iswara

2) Arah selatan sebagai Dewa Brahma

3) Arah barat sebagai Mahadewa 
4) Arah utara sebagai Dewa Wisnu

5) Arah tenggara sebagai Maheswara

6) Arah barat daya sebagai Dewa Rudra

7) Arah barat laut sebagai Sankara

8) Arah timur laut sebagai Sambhu

9) Tengah sebagai Dewa Siwa

Penyungsung pura dari keempat pura diantaranya PuraBatu Medau penyungsung pura yang terdiri dari 6 desa yaitu Desa Kutampi, Kutampi Kaler, Batununggul, Suana, Tanglad, dan Pejukutan dan 9 orang sebagai pengurus pura, Pura Goa Giri Putri yang merupakan Dusun Karang Sari sebagai penyungsung pura dan 2 kelompok yaitu kelompok pertama dan kedua yang sebagai pengayah terdiri dari masing-masing 12 orang sebagai pengurus pura, Pura Puncak Mundi terdapat sebelas banjar adat yang menjadi penyungsung di antaranya Banjar Baledan Duur, Banjar Baledan Beten, Banjar Klumpu Kauh, Banjar Klumpu Kangin, Banjar Angas, Banjar Mentaki, Banjar Rata, Banjar Tiagan, Banjar Bila, Banjar Cubang dan Banjar Iseh dan 19 orang sebagai pengurus pura setiap harinya. dan Pura Penataran Agung Ped yaitu seluruh Desa yang ada di Nusa Penida merupakan penyungsung Pura tetapi hanya 18 orang dibentuk panitia sebagai pengurus pura.

Fungsi pura, Bangi Masyarakat Hindu, Pura itu merupakan tempat melakukan persembahyangan. Bagi masyarakat luar atau wisatawan berbeda karena tourist karena menurut tourist wisata spiritual merupakan salah satu objek wisata karena Pulau Nusa Penida terkenal banyak wisata diantaranya wisata alam, wisata spiritual sehingga wisatawan tertarik untuk berkunjung ke wisata spiritual. Hasil penelitian ini sesuai dengan temuan Gelebet (2008) hasil penelitiannya menyatakan bahwa karakteristik wisata spiritual mempunyai beberapa bagian seperti tipologi bangunan suci pada kompleks pura, susunan pura sebagai kompleks bangunan, orientasi pura, sasaran yang dipuja, penyungsung pura, dan fungsi pura.

\subsection{Pemetaan Jalur Wiata Spiritual di Kecamatan Nusa Penida}

Sebelum pemedek atau pengunjung melakukan persembahyangan ke Nusa Penida, pemedek atau pengunjung yang dari luar Nusa Penida terlebih dahulu menyebrang dengan transportasi laut karena Nusa Penida merupakan Pulau yang terpisah dengan Bali yang merupakan kabupaten Klungkung, pertama dari rumah masing-masing menuju tempat penyeberangan atau pelabuhan. Terdapat empat tempat penyeberangan atau pelabuhan yang berbeda yaitu: (1) Padang Bai dengan menggunakan kapal roro dan turun di Kutampi Nusa Penida (2) Pesinggahan dengan menggunakan boat turun di Buyuk Nusa Penida (3) Kusamba dengan menggunakan boat turun di Sampalan Nusa Penida (3) Sanur dengan menggunakan boat turun di berbeda tempat ada di Buyuk Nusa Penida dan ada di Toya Pakeh Nusa Penida sesuai dengan boat yang dinaiki.

Pemilihan rute adalah salah satu indikator penting dalam pergerakan orang dan kendaraan dalam mencapai tujuan. Setiap orang menginginkan efisiensi waktu, jarak, 
biaya dan kenyamanan dalam menentukan rute terbaik. Pengunjung atau pemedek yang dulu biasanya naik kapal roro untuk menyeberang sekarang para pemedek lebih banyak menggunakan boat untuk menyeberang dibandingkan kapal roro karena kecepatan antara boat dengan kapal lebih cepat boat yaitu kalau naik kapal perjalanan kurang lebih 1 jam sedangkan boat dengan kecepatan kurang lebih 20 menit dan ada yang kurang lebih 30 menit sehingga pemedek lebih banyak naik boat dan tempat penyeberangan lebih banyak di sanur dan di pesinggahan karena boat yang naik di pelabuhan pesinggahan dan sanur turunnya sama yaitu di buyuk dan mobil yang mengantar jemput sudah menunggu di Buyuk karena Cuma di Buyuk yang merupakan tempat antar jemput dengan jumlah sopir serta mobil 43 yang mana mobil yang dapat menjemput pemedek sesuai nomor yang didapat, nomor mobil setiap harinya terus bergantian sehingga sopir yang mendapat nomor urutan pertama dan seterusnya sudah bersiap di lokasi.

Sampai di Nusa Penida para Pemedek sudah di tunggu beberapa mobil yang satu mobil memuat 10 pemedek. Setelah pemedek berada di dalam mobil, sopir langsung membawa pemedek mulai melakukan persembahyangan ke pura yaitu pura pertama menuju ke Pura Goa Giri Putri, di Pura Goa Giri Putri melakukan persembahyangan 5 kali, di luar goa terdapat satu pelinggih dan 4 pelinggih berada di dalam goa. Kondisi jalan menuju Pura Goa Giri Putri luas dan bagus sehingga lebih cepat sampai di lokasi. Selanjutnya pemedek menuju ke pura kedua yaitu Pura Batu Medau yang tidak jauh dengan Pura Goa Giri Putri, setelah sampai di lokasi pemedek langsung melakukan persembahyangan pertama yaitu Pura Segara kemudian Pura Taman dan terakhir Pura Penataran Agung.

Pemedek selanjutnya melakukan persembahyangan ke Pura Puncak Mundi yang berada di bukit paling tinggi dengan kondisi jalan yang kurang baik dan sempit, suasana di Pura Puncak Mundi juga dingin. Sampai di Pura Puncak Mundi pemedek langsung melakukan persembahyangan ke 4 lokasi, dan yang terakhir pemedek sembahyang di Pura Penataran Ped dan mekemit atau menginap di Pura Penataran Ped, di Pura Penataran Agung Ped pemedek melakukan persembahyangan 4 pura. Pura Penataran Agung Ped merupakan pura yang terakhi dan sebagai tempat menginap atau mekemit sebelum pemedek kembali ke rumah karena jarak pelabuhan dengan Pura Penataran Agung Ped sangat dekat dibandingkan dengan ketiga pura lainnya sehingga pemedek lebih gampang dan lebih cepat untuk pulang keesokan harinya.

Hasil penelitian ini sesuai dengan temuan Anam (2016) hasil penelitiannya menyatakan bahwa dalam melakukan perjalanan dari suatu tempat asal ke tempat tujuan, perjalanan dengan rute terbaik menjadi harapan setiap orang. Rute terbaik yang dimaksudkan disini adalah rute perjalanan yang kemungkinan besar memiliki waktu tempuh tercepat. Rute terbaik pada umumnya adalah berdasarkan jarak tempuh dari suatu tempat ke tempat yang lain. Pada kenyataannya rute terbaik seharusnya memperhatikan kondisi jalan misalnya kapasitas jalan, banyak kendaraan yang melewati, jarak tempuh dan lain-lain. 


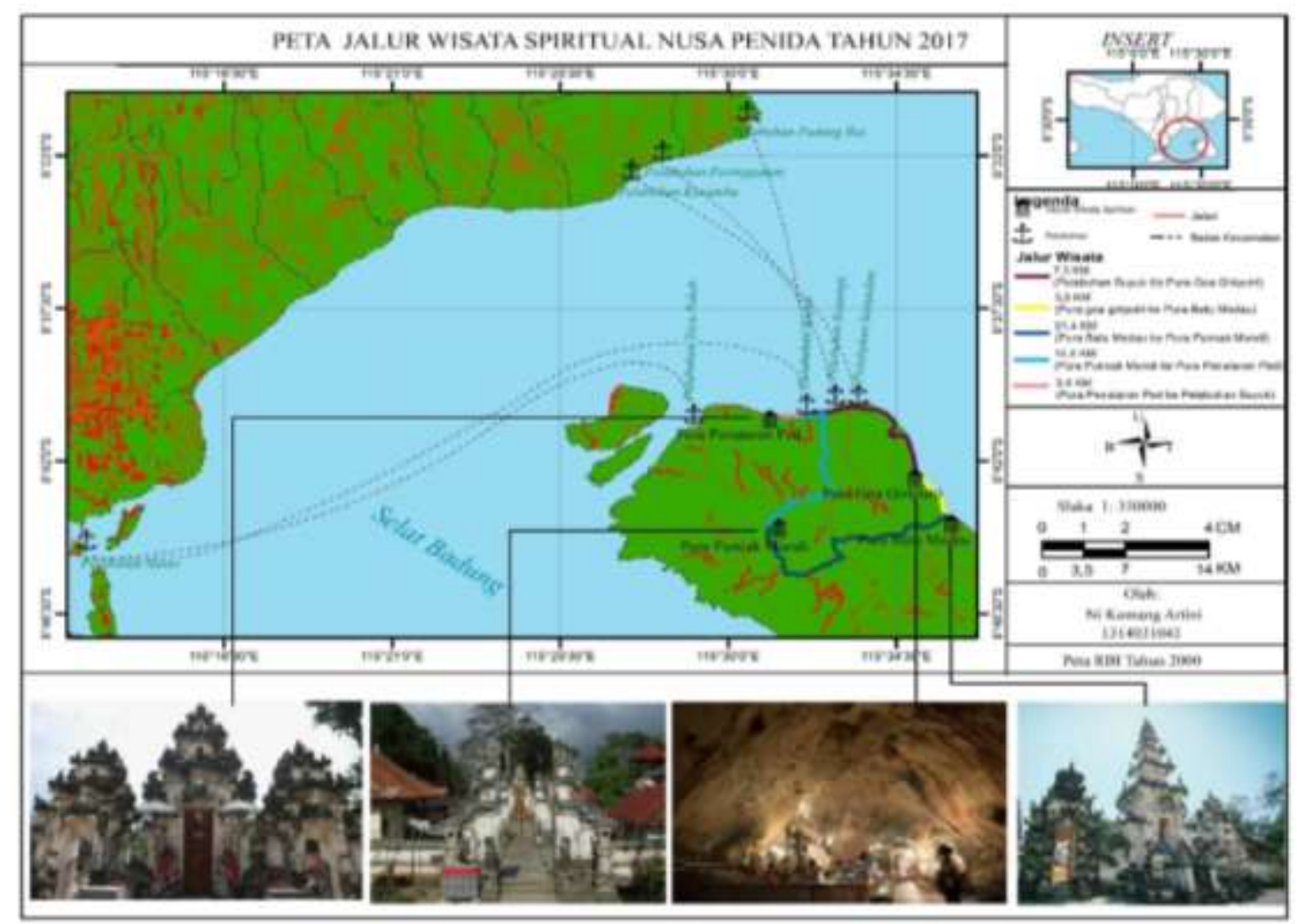

Gambar 4. Peta Jalur Wisata Spiritual Nusa Penida

\section{Simpulan dan saran}

Karakteristik wisata spiritual di Kecamatan Nusa Penida memiliki perbedan dan persamaan. Perbedaan dapat dilihat dari tipologi bangunan pelinggih, susunan pada setiap pura, sasaran yang dipuja, kemudian yang menjadi persamaan pada karakteristik pura yaitu orientasi pura, penyungsung pura serta fungsi pura dan Urutan jalur wisata spiritual dapat dilihat dari urutan pertama hingga terakhir yaitu Pura Goa Giri Putri, Pura Batu Medau, Pura Puncak Mundi dan Pura Penataran Ped.

Peneliti selanjutnya bisa mengadakan penelitian mengenai lokasi yang sama dengan sudut pandang berbeda, namun dengan variabel pemetaan jalur wisata spiritual. Hasil dari penelitian ini diharapkan dapat dijadikan referensi atau acuan kepada peneliti lain yang berminat untuk melakukan penelitian sejenis, dapat digunakan sebagai perbandingan atau pertimbangan dengan memperhatikan kendala-kendala yang dialami untuk perbaikan dan penyempurnaan pelaksanaan penelitian.

Penelitian ini dapat dijadikan sebagai bahan masukan dalam pemetaan jalur wisata spiritual di Kecmtan Nusa Penida sehingga bisa mempermudah pengunjung yang datang melakukan persembahyangan. Dapat memberikan informasi mengenai Kecamatan Nusa Penida yang memiliki wisata spiritual yang dapat membantu masyarakat Nusa Penida dalam perekonomian. 


\section{Daftar Rujukan}

Aditya, I. W. P., Suwena, I. K., \& Sudana, I. P. (2016). Studi Eksplorasi Pariwisata Spiritual di Sentra Pariwisata Ubud Gianyar (Studi Kasus di Ubud Bodywork Centre dan Yoga Barn). Jurnal IPTA, 4(1), 26-31.

Anam, S. (2016). Pencarian Rute Terbaik Menggunakan Logika Fuzzy dan Algoritma Semut. Jurnal Konferensi Nasional Penelitian Matematika Dan Pembelajarannya KNPMP I, 24(1), 873-874.

Arjana, I. G. B. (2016). Geografi PariwisatadanEkonomi Kreatif. Jakarta: Rajawali.

Damasdino, F. (2015). Studi Karakteristik Wisatawan dan Upaya Pengembangan Produk Wisata Tematik di Pantai Goa Cemara Pantai Kuwaru dan Pantai Pandansimo Baru Kabupaten Bantul. Jurnal Media Wisata, 13(2), 308-320.

Dwiyasa, I. B. P., \& Citra, I. P. A. (2014). Partisipasi Masyarakat Lokal Dalam Pengembangan Ekowisata di Desa Pemuteran. Media Komunikasi Geografi, 15(2), 30-42.

Gelebet. (2008). Tinjauan Dan Perbandingan Arsitektur Pura Maospait Dengan Beberapa Kuna Lain di Bali. Jurnal Wisata Spiritual Lintas Agama, 38(2), 59-75.

Herman, N. N., \& Supriadi, B. (2017). Potensi Ekowisata dan Kesejahteraan Masyarakat. Pesona, $2(2), 1-12$.

Marpaung, H. (2002). Pengantar Pariwisata. Bandung: Alfabeta.

Sukadi, R. M. (2001). New Age WisataSpiritual Lintas Agama. Journal Speed-Sentral Penelitian, 6(4).

Suwirmayanti, N. L. G. P. (2016). Sistem Informasi Pemetaan Wisata Fauna di Bali. Techno.COM, 15(3), 182-189. 